\title{
A Prospective Study Comparing Cancer Detection Rates of Transperineal Prostate Biopsies Performed by Junior Urologists Versus a Senior Consultant in a Real World-setting
}

\author{
Jiaao Song \\ Changhai hospital \\ Bi-ming He \\ Changhai hospital \\ Hu-sheng Li \\ Changhai hospital \\ Zhen-kai Shi \\ Changhai hospital \\ Guan-yu Ren \\ Changhai hospital \\ Huan Chen \\ Changhai hospital \\ Chuan-liang Xu \\ Changhai hospital \\ Xu Gao \\ Changhai hospital \\ Shu-xiong Zeng ( $\nabla$ zengshuxiong@126.com ) \\ Changhai hospital \\ Hai-feng Wang \\ Changhai hospital
}

\section{Research Article}

Keywords: prostate cancer, fusion biopsy, magnetic resonance imaging, ultrasonography, learning curve

Posted Date: December 7th, 2020

DOl: https://doi.org/10.21203/rs.3.rs-120286/v1

License: (c) (i) This work is licensed under a Creative Commons Attribution 4.0 International License.

Read Full License 
Page 2/14 


\section{Abstract}

Background: Prostate biopsy (PB) is a typical daily practice method for the diagnosis of prostate cancer (PCa). This study was to compare the PCa detection rate and peri- and post-operative complications of PB among three residents and a consultant.

Methods: A total of 343 patients who underwent PB between August 2018 with July 2019 were involved in this study. Residents were systematically trained two weeks by the consultant for performing systemic biopsy (SB) and targeted biopsy (TB). And then, three residents and the consultant performed PB independently every quarter due to routine rotation in daily practice. The peri- and post-operative data was prospectively collected. The primary outcome and secondary outcome were to compare the PCa-detection rates and complications between residents and consultant, respectively.

Results: There was no significant difference between the residents and consultant in terms of overall PCa-detection rates of SB, TB or further stratified by prostate specific antigen value, prostate imaging reporting and data system (PI-RADS) scores. We found the consultant had more TB cores compared with residents ( 175 cores versus 86 to 114 cores, $P=0.043$ ) and shorter procedural time versus residents (mean 16 min versus 19.7 to $20.1 \mathrm{~min}, \mathrm{P}<0.001$ ). The complication rate for consultant was $6.7 \%$, and $5 \%$ to $8.2 \%$ for residents, respectively $(P=0.875)$.

Conclusions: The residents could get a similar PCa detection and complication rates compared with the consultant after a two-week training. However, the residents still need more cases to shorten the time of biopsy procedure.

\section{Background}

Prostate cancer (PCa) is a common cancer in men. In 2018, there are more than 1.27 million new cases and 359,000 associated deaths worldwide, which makes it the second most frequent cancer and the fifth leading cause of cancer death in men[1]. Prostate biopsy (PB) is an important method for diagnosing and further staging. Currently, the most widely used biopsy method is 12-cores system biopsy (SB). However, underdiagnosis and undertreatment occur because of the errors of sampling and grading[2]. The falsenegative rate of $\mathrm{SB}$ is $11-13 \%[3,4]$. It also has the limitations of overdiagnosis to the patients with low risk cancers[3]. Multi-parametric magnetic resonance imaging (mpMRI) is more sensitive than the ultrasound-guided prostate biopsy (TRUS-biopsy) in clinically significant cancer (csPCa)[5]. And MRItargeted biopsies (TB) can improve the detection in high grade cancers[6-8].

Though TB is better than SB in diagnosis[7], patients underwent both SB and TB have higher detection rates[9]. So, a combined MRI-target and systematic biopsies (CB) are implied to get better effects. CB have higher detection rate and less error in upgrades than with either method alone[6,9]. Several studies have investigated the learning curve of both SB and TB. Kasabwala et al. found that the detection rates of the TB increased after 98 cases and the decrease in fibromuscular tissue in SB after 84 cases[10]. The time of the TB also shortened after training for cases[11, 12]. 
Professional skills and rich experience are required to make sure high detection rates in CB. But how long time a resident needed to master this procedure is unknow. Three residents were trained by an experienced consultant for SB and TB for two weeks' training schedule. This study prospectively investigated the PCa detection rate and peri- and post-operative complications of PB among three residents and consultant.

\section{Methods}

\section{Study population}

From August 2018 to July 2019, clinical and pathological information of patients who underwent PB in Shanghai Changhai Hospital were prospectively maintained in our database. During this time of period, four urologists, including one consultant (Hai-feng Wang) and three junior residents (A, Shu-xiong Zeng; $\mathrm{B}, \mathrm{Bi}$-ming He; C, Guan-yu Ren) independently performed PB for each quarter according to routinely rotation and clinical practice. We screened for consecutive patients who underwent PB performed by these different urologists. The consultant had $>20$ years of urological experience, and performed $>$ 2000 PB with SB, TB and CB techniques. The junior residents had 2 to 3 years of urological experience, and had the training course for PB directed by the consultant for two weeks in a row. The training arrangement was shown in Fig. 1, each resident initially began with local anesthesia, and then performed SB for patients under the supervision of consultant, thereafter followed by cognitive mpMRI and ultrasound fusion TB. During the training course, every resident independently performed 20 to $30 \mathrm{~PB}$ including SB and CB techniques under the supervision of the consultant. Residents would qualify for PB when met the standard of identifying suspicious lesions from mpMRI and ultrasound, becoming skilled with the procedures of PB and being familiar with how to manage potential complications after PB. Written informed consent was obtained from each patient in this study. This study protocol was approved by the ethical board of Changhai Hospital and in accordance with the ethical guidelines outlined in the Declaration of Helsinki.

\section{Patient management}

Indications to perform PB included: elevated prostate-specific antigen (PSA), abnormal total-PSA/ freePSA ratio, abnormal digital rectal examination (DRE), positive mpMRI (Prostate Imaging Reporting and Data System, PI-RADS $\geq 3$ ) or regular MRI (lesions suspected on MRI only had the T1-weighted and T2weighted imaging sequences). Indications to have mpMRI examination prior to PB or following a previous negative PB in our center were at the referring urologists' discretion. Some patients already had $\mathrm{mpMRI}$ or regular MRI in other hospitals before referred to our center for PB. All patients had undergone the SB. Patients with suspicious lesions on mpMRI had undergone CB. We also performed TB for patients with suspicious lesions on ultrasound images. Patients were excluded for analysis: patients had any prior therapy for PCa, patients asked for a certain urologist for PB; patients required PB under general anesthesia. We used numeric rating scale (NRS) of pain which is a scale ranging from 0 to 10 , with 0 representing no pain and 10 representing unbearable pain. The patients chose a number to describe the pain immediately after biopsy. 


\section{Biopsy technique}

Oral levofloxacin was administered once daily starting the day before procedure. PB were performed under the guidance of an ultrasound device (Flex focus 800, Peabody, MA, USA), which equipped with a bi-planar transrectal transducer (8848, BK Ultrasound, Peabody, MA, USA) under local anesthesia[13]. We used a biopsy gun (Magnum MG15-22; Bard, Tempe, AZ, USA) equipped with a biopsy needle (18G, 130; Bard) to perform the biopsy procedure. The SB region was described before[14]. TB was using freehand without any other auxiliary tools[15]. Three cores were taken for each suspicious lesion. The details of the biopsy procedure were shown in our previous study[16].

\section{End points and statistical analyses}

The primary outcome was overall PCa-detection rate of PB. The secondary outcomes were PCa-detection rate stratified by SB and TB approach, PSA level and PI-RADS scores; the complications during or after PB; Self-reported numeric pain rating scale. Data were analyzed using SPSS 22.0 (IBM, Armonk, NY, USA). Categorical data were compared between groups using the Chi-square, Continuity Correction or Fisher's exact test, while continuous data were compared by Analysis of Variance or the Kruskal-Wallis $\mathrm{H}$ test. All $P$ values were two-sided, and a difference of $P<0.05$ was considered statistically significant.

\section{Results}

Three junior residents were trained through the mentioned training mode for 2-week in advance by the same consultant before performing the biopsy independently. Biopsies were performed by one consultant and three junior residents independently every quarter from August 2018 to July 2019. In total, 343 patients were identified as suitable for inclusion in the study. 25 patients were excluded for general anesthesia. 31 patients were excluded for prior therapy for $\mathrm{PCa}$.

\section{Patient characteristics}

The median age of the entire cohort was 67.25 years, and the median PSA was $11.89 \mathrm{ng} / \mathrm{ml}$. Consultant and three residents performed $90,85,88$ and 80 transperineal prostate biopsies respectively. Clinical characteristics of the patients in each group were shown in Table 1. There were no significant differences amongst groups in terms of age, PSA levels, the rate of patients underwent the mpMRI, and the comorbidity. 
Table 1

Patient characteristics

\begin{tabular}{|c|c|c|c|c|c|}
\hline & Resident A & Resident B & Resident C & Consultant & $\mathbf{P}$ \\
\hline Sample size & 85 & 88 & 80 & 90 & \\
\hline Body mass index & $24.61 \pm 3.09$ & $23.98 \pm 2.93$ & $24.58 \pm 2.74$ & $24.33 \pm 2.68$ & 0.440 \\
\hline Age, year (range) & $\begin{array}{l}67.32 \pm \\
9.18(39-89)\end{array}$ & $\begin{array}{l}67.51 \pm \\
7.44(45-84)\end{array}$ & $\begin{array}{l}66.54 \pm \\
7.84(47-84)\end{array}$ & $\begin{array}{l}67.57 \pm \\
9.87(41-87)\end{array}$ & 0.792 \\
\hline $\begin{array}{l}\text { Median PSA, ng/ml } \\
\text { (IQR) }\end{array}$ & $\begin{array}{l}10.97(7.37- \\
24.21)\end{array}$ & $\begin{array}{l}12.76(7.55- \\
31.37)\end{array}$ & $\begin{array}{l}11.92(7.86- \\
32.71)\end{array}$ & $\begin{array}{l}\text { 16.28(8.40- } \\
51.00)\end{array}$ & 0.311 \\
\hline $\begin{array}{l}\text { Cases had mpMRI } \\
(\mathrm{n} \%)\end{array}$ & $33(38.8 \%)$ & $32(36.4 \%)$ & $26(32.5 \%)$ & $46(51.1 \%)$ & 0.071 \\
\hline $\begin{array}{l}\text { Number of positive } \\
\text { mpMRI ( } \mathrm{n} \%)\end{array}$ & $17(20.0 \%)$ & $19(21.6 \%)$ & $16(20.0 \%)$ & $28(31.1 \%)$ & 0.239 \\
\hline Hypertension (n\%) & $35(41.2 \%)$ & $29(32.95 \%)$ & $33(41.25 \%)$ & $31(34.4 \%)$ & 0.551 \\
\hline $\begin{array}{l}\text { Coronary heart } \\
\text { disease }(\mathrm{n} \%)\end{array}$ & $2(2.4 \%)$ & $4(4.55 \%)$ & $1(1.25 \%)$ & $2(2.2 \%)$ & 0.629 \\
\hline Diabetes (n\%) & $5(5.9 \%)$ & $7(7.95 \%)$ & $9(11.25 \%)$ & $7(7.8 \%)$ & 0.653 \\
\hline
\end{tabular}

\section{Detection rates of prostate cancer}

As shown in Table 2, procedural time was significantly shorter for consultant versus residents (mean 16 min versus 19.7 to $20.1 \mathrm{~min}, \mathrm{P}<0.001$ ). The proportions of PCa-positive biopsy were similar among the consultant and three residents. The detection rates of PCa were $61.1 \%, 54.1 \%, 58.0 \%$ and $52.5 \%$ for consultant and three residents, respectively $(P=0.733)$. Specifically, when stratified the approach of biopsy as SB and TB, no statistically significant differences for PCa detection rate for consultant and three residents. As for the number of TB cores, consultant had performed more TB cores compared with residents ( 175 cores versus 86 to 114 cores, $P=0.043$ ), because more suspected lesions by mpMRI or ultrasound in the consultant group. However, there were no significant differences in the rates of PCapositive TB cores between consultant and residents $(43.4 \%$ versus $47.4-55.8 \%, P=0.224)$. As for TB for lesions suspected by the urologists but with PI-RADS $<3$, the positive rates were 1/6 (16.7\%), 0/2 (0.0\%), $1 / 4$ (25.0\%), 2/6 (33.3\%), for A to C residents and consultant, respectively. The biopsy results of Gleason scores were summarized in Table 3. No obvious difference in Gleason scores was identified between the consultant and residents. Biopsies performed by consultant yielded the rates of Gleason $\geq 3+4$ of $55.6 \%$, and the rates of residents ranged from $46.3-53.4 \%(P=0.568)$. 
Table 2

The outcome of prostate biopsies between groups of residents and consultant

\begin{tabular}{|c|c|c|c|c|c|c|}
\hline & & $\begin{array}{l}\text { Resident } \\
\text { A }\end{array}$ & $\begin{array}{l}\text { Resident } \\
\text { B }\end{array}$ & $\begin{array}{l}\text { Resident } \\
\text { C }\end{array}$ & Consultant & $\mathbf{P}$ \\
\hline \multicolumn{2}{|l|}{ Time of $\mathrm{PB}(\mathrm{min})$} & $\begin{array}{l}20.1 \pm \\
2.7\end{array}$ & $\begin{array}{l}19.7 \pm \\
3.1\end{array}$ & $\begin{array}{l}20.0 \pm \\
2.9\end{array}$ & $16.0 \pm 2.6$ & $\begin{array}{l}< \\
0.0001\end{array}$ \\
\hline \multirow[t]{3}{*}{$\begin{array}{l}\text { Overall positive rates of } \\
\text { PB }\end{array}$} & & $\begin{array}{l}54.1 \% \\
(46 / 85)\end{array}$ & $\begin{array}{l}58.0 \% \\
(51 / 88)\end{array}$ & $\begin{array}{l}53.8 \% \\
(43 / 80)\end{array}$ & $\begin{array}{l}61.1 \% \\
(55 / 90)\end{array}$ & 0.733 \\
\hline & $\begin{array}{l}\text { Positive } \\
\text { rates of } \\
\text { SB }\end{array}$ & $\begin{array}{l}54.1 \% \\
(46 / 85)\end{array}$ & $\begin{array}{l}58.0 \% \\
(51 / 88)\end{array}$ & $\begin{array}{l}52.5 \% \\
(42 / 80)\end{array}$ & $\begin{array}{l}61.1 \% \\
(55 / 90)\end{array}$ & 0.666 \\
\hline & $\begin{array}{l}\text { Positive } \\
\text { rates of } \\
\text { TB }\end{array}$ & $\begin{array}{l}52.9 \% \\
(18 / 34)\end{array}$ & $\begin{array}{l}64.3 \% \\
(18 / 28)\end{array}$ & $\begin{array}{l}57.1 \% \\
(16 / 28)\end{array}$ & $\begin{array}{l}51.0 \% \\
(25 / 49)\end{array}$ & 0.707 \\
\hline \multicolumn{2}{|l|}{$\begin{array}{l}\text { Positive rates of TB } \\
\text { cores }\end{array}$} & $\begin{array}{l}47.4 \% \\
(54 / 114)\end{array}$ & $\begin{array}{l}55.8 \% \\
(48 / 86)\end{array}$ & $\begin{array}{l}52.9 \% \\
(46 / 87)\end{array}$ & $\begin{array}{l}43.4 \% \\
(76 / 175)\end{array}$ & 0.224 \\
\hline \multirow[t]{2}{*}{$\begin{array}{l}\text { Positive rates of TB with } \\
\text { different MRI approach }\end{array}$} & $\begin{array}{l}\text { With } \\
\text { mpMRI }\end{array}$ & $\begin{array}{l}52.2 \% \\
(12 / 23)\end{array}$ & $\begin{array}{l}66.7 \% \\
(12 / 18)\end{array}$ & $\begin{array}{l}64.7 \% \\
(11 / 17)\end{array}$ & $\begin{array}{l}55.6 \% \\
(20 / 36)\end{array}$ & 0.736 \\
\hline & $\begin{array}{l}\text { With } \\
\text { regular } \\
\text { MRI }\end{array}$ & $\begin{array}{l}54.5 \% \\
(6 / 11)\end{array}$ & $\begin{array}{l}60.0 \% \\
(6 / 10)\end{array}$ & $\begin{array}{l}45.5 \% \\
(5 / 11)\end{array}$ & $\begin{array}{l}38.5 \% \\
(5 / 13)\end{array}$ & 0.740 \\
\hline \multirow[t]{4}{*}{$\begin{array}{l}\text { Positive rates of TB with } \\
\text { PI-RADS stratification }\end{array}$} & & $\begin{array}{l}64.7 \% \\
(11 / 17)\end{array}$ & $\begin{array}{l}75.0 \% \\
(12 / 16)\end{array}$ & $\begin{array}{l}76.9 \% \\
(10 / 13)\end{array}$ & $\begin{array}{l}75.0 \% \\
(18 / 24)\end{array}$ & 0.886 \\
\hline & 3 & $\begin{array}{l}66.7 \% \\
(2 / 3)\end{array}$ & $\begin{array}{l}40.0 \% \\
(2 / 5)\end{array}$ & $\begin{array}{l}60.0 \% \\
(3 / 5)\end{array}$ & $\begin{array}{l}33.3 \% \\
(2 / 6)\end{array}$ & 0.805 \\
\hline & 4 & $\begin{array}{l}55.6 \% \\
(5 / 9)\end{array}$ & $\begin{array}{l}83.3 \% \\
(5 / 6)\end{array}$ & $\begin{array}{l}83.3 \% \\
(5 / 6)\end{array}$ & $\begin{array}{l}88.9 \% \\
(8 / 9)\end{array}$ & 0.442 \\
\hline & 5 & $\begin{array}{l}80.0 \% \\
(4 / 5)\end{array}$ & $\begin{array}{l}100.0 \% \\
(5 / 5)\end{array}$ & $\begin{array}{l}100.0 \% \\
(2 / 2)\end{array}$ & $\begin{array}{l}88.9 \% \\
(8 / 9)\end{array}$ & 1.000 \\
\hline \multicolumn{2}{|l|}{$\begin{array}{l}\text { Positive rates of TB with } \\
\text { PI-RADS }<3\end{array}$} & $\begin{array}{l}16.7 \% \\
(1 / 6)\end{array}$ & $\begin{array}{l}0.0 \% \\
(0 / 2)\end{array}$ & $\begin{array}{l}25.0 \% \\
(1 / 4)\end{array}$ & $\begin{array}{l}33.3 \% \\
(2 / 6)\end{array}$ & \\
\hline \multicolumn{2}{|l|}{ Median NRS (IQR) } & $\begin{array}{l}2.00 \\
(0.00- \\
3.00)\end{array}$ & $\begin{array}{l}2.00 \\
(1.00- \\
3.00)\end{array}$ & $\begin{array}{l}1.50 \\
(0.25- \\
2.00)\end{array}$ & $\begin{array}{l}2.00 \\
(1.00- \\
3.00)\end{array}$ & 0.085 \\
\hline \multicolumn{7}{|c|}{ PB: Prostate biopsy; SB: Systematic biopsy; TB: Targeted biopsy; PI-RADS: Prostate imaging } \\
\hline
\end{tabular}


Table 3

The Gleason Scores of biopsies with prostate cancer

\begin{tabular}{|lllll|}
\hline Gleason Scores & $\mathbf{6}$ & $\mathbf{3 + 4}$ & $\mathbf{4 + 3}$ & $\mathbf{8}$ or higher \\
\hline Consultant $(\mathrm{n} \%)$ & $5(9.1 \%)$ & $12(21.8 \%)$ & $10(18.2 \%)$ & $28(50.9 \%)$ \\
\hline Resident $\mathrm{A}(\mathrm{n} \%)$ & $5(10.9 \%)$ & $12(26.1 \%)$ & $8(17.4 \%)$ & $21(45.7 \%)$ \\
\hline Resident B(n\%) & $1(2.1 \%)$ & $15(31.3 \%)$ & $11(22.9 \%)$ & $21(43.8 \%)$ \\
\hline Resident C(n\%) & $4(9.8 \%)$ & $10(24.4 \%)$ & $5(12.2 \%)$ & $22(53.7 \%)$ \\
\hline
\end{tabular}

Table 4 presented the PCa-detection rates of systemic and targeted biopsy further stratified by PSA value, and there was no statistical difference in the detection rate for PCa in different levels of PSA between consultant and residents. The only significant difference was captured for SB at PSA value between 20 to $100 \mathrm{ng} / \mathrm{ml}$ between resident $A$ and resident $C(94.4 \%$ versus $66.7 \%, P=0.049)$. Further analysis revealed more patients underwent mpMRI at PSA value of 20 to $100 \mathrm{ng} / \mathrm{ml}$ in resident $A$ group compared with resident $B$ group ( 5 versus $2, P<0.001$ ), which suggested mpMRI might contributed to the detection of suspected lesions in SB. There was no significant difference in the rate of PCa-detection for TB of lesions with PI-RADS score $\geq 3$ in mpMRI between consultant and residents $(75.0 \%$ versus $64.7-76.9 \%, P=$ 0.886). The PCa-detection rates of TB with different PI-RADS scores of mpMRI were also examined, there was also no statistical difference among the consultant and residents (Table 4). 
Table 4

PCa-detection rates of systemic and targeted biopsies stratified by PSA value

\begin{tabular}{|c|c|c|c|c|c|c|}
\hline & & Resident A & Resident B & Resident C & Consultant & $P$ \\
\hline \multirow{4}{*}{$\begin{array}{l}\text { Positive cases } \\
\text { of SB stratified } \\
\text { by PSA } \\
\text { value/total(n\%) }\end{array}$} & $\begin{array}{l}0- \\
10\end{array}$ & $10 / 40(25.0 \%)$ & $12 / 35(34.3 \%)$ & 10/32(31.3\%) & $10 / 36(27.8 \%)$ & 0.832 \\
\hline & $\begin{array}{l}10- \\
20\end{array}$ & $10 / 18(55.6 \%)$ & $15 / 24(62.5 \%)$ & $11 / 20(55.0 \%)$ & $13 / 19(68.4 \%)$ & 0.807 \\
\hline & $\begin{array}{l}20- \\
100\end{array}$ & 17/18(94.4\%) & $15 / 20(75.0 \%)$ & $14 / 21(66.7 \%)$ & $19 / 22(86.4 \%)$ & 0.135 \\
\hline & $\begin{array}{l}> \\
100\end{array}$ & $9 / 9$ & $9 / 9$ & $7 / 7$ & $13 / 13$ & \\
\hline \multirow{4}{*}{$\begin{array}{l}\text { Positive cases } \\
\text { of TB stratified } \\
\text { by PSA } \\
\text { value/total(n\%) }\end{array}$} & $\begin{array}{l}0- \\
10\end{array}$ & 5/18(27.8\%) & 8/15(53.3\%) & 7/11(63.6\%) & 9/27(33.3\%) & 0.295 \\
\hline & $\begin{array}{l}10- \\
20\end{array}$ & $7 / 10(70.0 \%)$ & $6 / 9(66.7 \%)$ & $4 / 8(50.0 \%)$ & $10 / 13(76.9 \%)$ & 0.787 \\
\hline & $\begin{array}{l}20- \\
100\end{array}$ & $6 / 6(100.0 \%)$ & $4 / 4(100.0 \%)$ & $5 / 9(55.6 \%)$ & 6/9(66.7\%) & 0.191 \\
\hline & $\begin{array}{l}> \\
100\end{array}$ & 0 & 0 & 0 & 0 & - \\
\hline
\end{tabular}

\section{Complications of prostate biopsy}

As shown in Table 5, the complications were hematuria, fever, urinary retention and vaso-vagal reactions. The overall complication rate for consultant was $6.7 \%$, and $5-8.2 \%$ for residents $(P=0.875)$. Notably, the most frequent collateral event was hematuria of varied degrees, which occurs for nearly all patients at the first urination after biopsy and could resolve spontaneously. Only those patients with obvious gross hematuria after biopsy and managed with placement of catheter at the discretion of urologists to prevent formation of blood clot in bladder were recorded. Two patients had fever over $38.5^{\circ} \mathrm{C}$ within 24 hours after biopsy, and were treated with intravenous antibiotics. Three patients suffered urinary retention, and managed with indwelling catheter for 5 to 7 days and taken tamsulosin orally once a day. There were 13 patients experienced vaso-vagal reactions with symptoms of low blood pressure within 30 min after biopsy, and all of them recovered with continuous blood pressure monitoring and rest on bed. In terms of self-reported pain scale, there was no significant difference in NRS between the consultant and residents' groups $(P=0.085)$. 
Table 5

Complications after prostate biopsies

\begin{tabular}{|llllll|}
\hline & Resident A & Resident B & Resident C & Consultant & P \\
\hline Overall complications(n\%) & $7(8.2 \%)$ & $6(6.8 \%)$ & $4(5.0 \%)$ & $6(6.7 \%)$ & 0.875 \\
\hline Hematuria(n\%) & $2(2.4 \%)$ & $1(1.1 \%)$ & $1(1.3 \%)$ & $1(1.1 \%)$ & 0.877 \\
\hline Fever(n\%) & $1(1.2 \%)$ & $0(0.0 \%)$ & $0(0.0 \%)$ & $1(1.1 \%)$ & $1.000^{*}$ \\
\hline Urinary retention(n\%) & $1(1.2 \%)$ & $0(0.0 \%)$ & $0(0.0 \%)$ & $2(2.2 \%)$ & $1.000^{*}$ \\
\hline Vaso-vagal reactions(n\%) & $3(3.5 \%)$ & $5(5.7 \%)$ & $3(3.8 \%)$ & $2(2.2 \%)$ & 0.687 \\
\hline $\begin{array}{l}\text { *We just compared resident A and consultant in "fever" and "urinary retention" for no cases in these } \\
\text { complications. }\end{array}$ & & & & \\
\hline $\begin{array}{l}\text { tPatients with obvious gross hematuria and managed with placement of catheter at the discretion of } \\
\text { urologists to prevent formation of blood clot in bladder were recorded. }\end{array}$ \\
\hline
\end{tabular}

\section{Discussion}

DRE, PSA levels, imaging and biopsy are the basic screening methods for the prostate diseases[8]. PB are the gold stand for diagnosis of PCa. Early diagnosis of clinically significant PCa will make the health care easier and reduce the death rate. In the last decade, mpMRI were used to locate and target the suspicious area to decrease the cores needed in SB. TB and CB have become new methods in detecting PCa. Ahdoot et al. invested 2103 patients with PCa and demonstrated that the detection rates of TB and CB were $51.5 \%$ and $62.4 \%$, respectively. CB detected 208 more cases than either SB or TB alone[6]. Experience is an important factor for detection rate in TB, and the missed cases can be decreased with improved experience[17]. The novices do have a potential learning curve which would limit the detection accuracy in TB. Mager el at. demonstrated the need for more than 63 biopsies to reach a steady level[11]. And Halstuch et al. reported that the surgical time shorting and detection rates improving were happened after 110-125 cases[12]. However, it is still unknown how many PB junior urologists are needed to reach a comparable PCa detection rate as to experienced urologists.

In the present study, we found that a resident can get a similar PCa detection rate in PB compared with the experienced consultant after a two-week training schedule. Neither the total detection rates nor the csPCa (Gleason $\geq 3+4$ ) detection rates have significance difference between the residents and consultant when PB were performed independently. Nevertheless, the residents still need a longer time to perform the PB procedures than the consultant. Halstuch et al. demonstrated a decreased surgical time from $45 \mathrm{~min}$ to $15 \mathrm{~min}$ with transrectal and from $55 \mathrm{~min}$ to $18 \mathrm{~min}$ with transperineal[12]. Complication rate is another important parameter to evaluate a surgical procedure. In this study, we found no significant difference among groups in terms of complication rate after PB, which suggested longer procedure time in resident group did not result to higher complication rate. The positive rate of PB was further analyzed by PSA stratification, there was no statistically difference in the detection rate for PCa in 
different levels of PSA among groups. However, we found statistically difference between resident $A$ and resident $C$ at PSA value between 20 to $100 \mathrm{ng} / \mathrm{ml}$ in SB. Further analysis revealed that significant more cases had mpMRI evaluation at PSA level of 20 to $100 \mathrm{ng} / \mathrm{ml}$ in resident A group might contributed to this difference. This suggested that mpMRI might have better performance than ultrasound in 20 to $100 \mathrm{ng} / \mathrm{ml}$ PSA level in SB as it has higher detection rate in csPCa in TB.

There were still several limitations in our study. Firstly, the sample size of patients and residents were relatively small, further studies with larger sample size may warrant. Secondly, the patients were not assigned randomly, which might induce a selection bias. Finally, we mainly focused on the PCa detection rate of the PB as the primary outcome. Although we found the detection rate of PCa among groups were comparable, the procedure duration of PB in residents was still longer than the consultant. This suggests that more cases are still needed for the residents to get a further proficiency level.

\section{Conclusions}

The proposed two-week TP prostate biopsy training schedule is efficient, residents could get a similar PCa detection rates for different PSA levels in both TP, SB or CB compared with consultant. However, the residents still need more samples to shorten the time of biopsy procedure.

\section{Abbreviations}

PB $=$ Prostate biopsy

$\mathrm{SB}=$ Systemic biopsy

$\mathrm{TB}=$ Targeted biopsy

PI-RADS = Prostate imaging reporting and data system

$\mathrm{PCa}=$ Prostate cancer

$\mathrm{mpMRI}=$ Multi-parametric magnetic resonance imaging

$\operatorname{csPCa}=$ Clinically significant cancer

$\mathrm{CB}=$ Combined biopsies

PSA = prostate-specific antigen

$\mathrm{DRE}=$ digital rectal examination

\section{Declarations}

\section{Ethics approval and consent to participate}


The Shanghai Changhai Hospital Ethics Committee gave approval for this study. Written informed consent was obtained from each patient in this study.

Consent for publication

Not applicable.

\section{Availability of data and materials}

The datasets used during the current study are available from the corresponding author on reasonable request.

\section{Competing interests}

The authors declare that they have no competing interests.

\section{Funding}

This work was supported by the Shanghai Sailing Program under Grant 18YF1422700; National Natural Science Foundation of China under Grant 81772720, 81572509, 81802515, 81801854; and Shanghai Clinical Medical Center of Urological Diseases Program under Grant $2017 Z Z 01005$.

\section{Authors' contributions}

Data curation, Writing - original draft, Writing - review \& editing.: J Song, S Zeng, B He. Data curation: Z Shi, S Zeng, B He, H Li, G Ren, H Chen. Final approval, Study design: C Xu, X Gao, S Zeng, H Wang.

\section{Acknowledgements}

Not applicable.

\section{References}

1. Bray F, Ferlay J, Soerjomataram I, Siegel RL, Torre LA, Jemal A: Global cancer statistics 2018: GLOBOCAN estimates of incidence and mortality worldwide for 36 cancers in 185 countries. $C A$ Cancer J Clin 2018, 68(6):394-424.

2. Padhani AR, Weinreb J, Rosenkrantz AB, Villeirs G, Turkbey B, Barentsz J: Prostate Imaging-Reporting and Data System Steering Committee: PI-RADS v2 Status Update and Future Directions. Eur Urol 2019, 75(3):385-396.

3. Schouten MG, van der Leest M, Pokorny M, Hoogenboom M, Barentsz JO, Thompson LC, Futterer JJ: Why and Where do We Miss Significant Prostate Cancer with Multi-parametric Magnetic Resonance Imaging followed by Magnetic Resonance-guided and Transrectal Ultrasound-guided Biopsy in Biopsy-naive Men? Eur Urol 2017, 71(6):896-903. 
4. Drost FH, Osses DF, Nieboer D, Steyerberg EW, Bangma CH, Roobol MJ, Schoots IG: Prostate MRI, with or without MRI-targeted biopsy, and systematic biopsy for detecting prostate cancer. Cochrane Database Syst Rev 2019, 4:CD012663.

5. Ahmed HU, El-Shater Bosaily A, Brown LC, Gabe R, Kaplan R, Parmar MK, Collaco-Moraes Y, Ward K, Hindley RG, Freeman A et al: Diagnostic accuracy of multi-parametric MRI and TRUS biopsy in prostate cancer (PROMIS): a paired validating confirmatory study. The Lancet 2017, 389(10071):815-822.

6. Ahdoot M, Wilbur AR, Reese SE, Lebastchi AH, Mehralivand S, Gomella PT, Bloom J, Gurram S, Siddiqui M, Pinsky P et al: MRI-Targeted, Systematic, and Combined Biopsy for Prostate Cancer Diagnosis. N Engl J Med 2020, 382(10):917-928.

7. Kasivisvanathan V, Rannikko AS, Borghi M, Panebianco V, Mynderse LA, Vaarala MH, Briganti A, Budaus L, Hellawell G, Hindley RG et al: MRI-Targeted or Standard Biopsy for Prostate-Cancer Diagnosis. N Engl J Med 2018, 378(19):1767-1777.

8. Mottet N, Cornford P, R.C.N. vdB: EAU guidelines prostate cancer. 2020.

9. Rouvière $O$, Puech P, Renard-Penna R, Claudon M, Roy C, Mège-Lechevallier F, Decaussin-Petrucci M, Dubreuil-Chambardel M, Magaud $L$, Remontet $L$ et al: Use of prostate systematic and targeted biopsy on the basis of multiparametric MRI in biopsy-naive patients (MRI-FIRST): a prospective, multicentre, paired diagnostic study. The Lancet Oncology 2019, 20(1):100-109.

10. Kasabwala K, Patel N, Cricco-Lizza E, Shimpi AA, Weng S, Buchmann RM, Motanagh S, Wu Y, Banerjee S, Khani F et al: The Learning Curve for Magnetic Resonance Imaging/Ultrasound Fusionguided Prostate Biopsy. Eur Urol Oncol 2019, 2(2):135-140.

11. Mager R, Brandt MP, Borgmann H, Gust KM, Haferkamp A, Kurosch M: From novice to expert: analyzing the learning curve for MRI-transrectal ultrasonography fusion-guided transrectal prostate biopsy. Int Urol Nephrol 2017, 49(9):1537-1544.

12. Halstuch D, Baniel J, Lifshitz D, Sela S, Ber Y, Margel D: Characterizing the learning curve of MRI-US fusion prostate biopsies. Prostate Cancer Prostatic Dis 2019, 22(4):546-551.

13. Wang H, Lin H, He B, Guo X, Zhou Y, Xi P, Liu Z, Li H, Xiao G, Wang M et al: A Novel Perineal Nerve Block Approach for Transperineal Prostate Biopsy: An Anatomical Analysis-based Randomized Single-blind Controlled Trial. Urology 2020.

14. He BM, Chen R, Shi ZK, Xiao GA, Li HS, Lin HZ, Ji J, Peng HX, Wang Y, Sun YH et al: Trans-Perineal Template-Guided Mapping Biopsy vs. Freehand Trans-Perineal Biopsy in Chinese Patients With PSA $<20$ ng/ml: Similar Cancer Detection Rate but Different Lesion Detection Rate. Front Oncol 2019, 9:758.

15. Wang HF, Chen R, He BM, Qu M, Wang Y, Lin HZ, Yang QS, Gao X, Sun YH: Initial experience with a novel method for cognitive transperineal magnetic resonance imaging-targeted prostate biopsy. Asian J Androl 2020, 22(4):432-436.

16. He B, Shi Z, Li H, Lin H, Yang Q, Lu J, Sun Y, Wang HJAoso: A Novel Prediction Tool Based on Multiparametric Magnetic Resonance Imaging to Determine the Biopsy Strategy for Clinically 
Significant Prostate Cancer in Patients with PSA Levels Less than 50 ng/ml. 2020, 27(4):1284-1295.

17. Meng X, Rosenkrantz AB, Huang R, Deng FM, Wysock JS, Bjurlin MA, Huang WC, Lepor H, Taneja SS: The Institutional Learning Curve of Magnetic Resonance Imaging-Ultrasound Fusion Targeted

Prostate Biopsy: Temporal Improvements in Cancer Detection in 4 Years. J Uro/ 2018, 200(5):10221029.

Figures

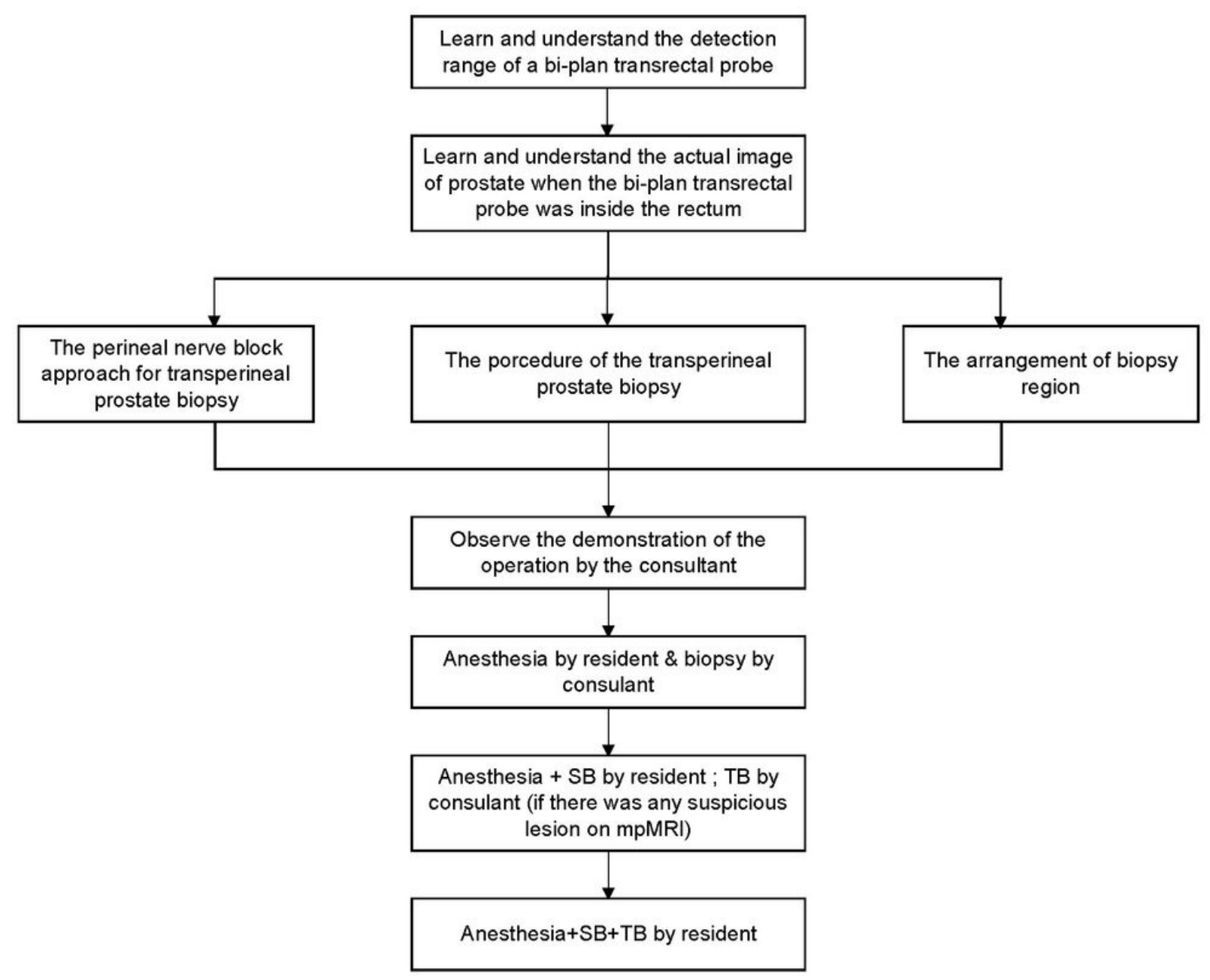

Figure 1

Training schedule for prostate biopsy 